\title{
The effect of marketing knowledge management on sustainable competitive advantage: Evidence from banking industry
}

\author{
Fatemeh Rezaee* and Mostafa Jafari
}

Department of Industrial Engineering (Digital Unit), Iran University of Science \& Technology, Tehran, Iran

\begin{tabular}{l}
\hline C H R O N I C L E \\
\hline Article history: \\
Received June 5, 2015 \\
Received in revised format \\
August 162015 \\
Accepted December 32015 \\
Available online \\
December 32015 \\
\hline Keywords: \\
Marketing knowledge \\
management \\
Sustainable competitive \\
advantage \\
Structural equation modelling \\
Banking industry
\end{tabular}

\section{Introduction}

In the late era, the managerial debate on related topics of marketing appears to have reached a crucial stage and during the last two decades its concept has witnessed considerable research (Carrillo et al., 2003; Carrion et al., 2004; Tsai \& Shih, 2004; Darroch, 2005; Lin \& Tseng, 2005; Tanriverdi, 2005; Young, 2006; Akroush \& Al-Mohammad, 2010; Hou \& Chien, 2010). However, there is no agreement among researchers about the precedents of marketing management. Previous studies have pointed out several precedents of marketing management, such as; external marketing, external customer,

* Corresponding author.

E-mail address: fh rezaee@ind.iust.ac.ir (F. Rezaee)

C 2015 Growing Science Ltd. All rights reserved. doi: $10.5267 /$ j.ac.2015.12.002

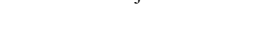


information technology, top management support and commitment, research and development, internal customer, internal marketing (Veismoradi et al., 2013, Kheiri et al., 2012). Furthermore, most of the extant research typically stops at identifying the precedents of marketing management, while the interactions and correlations among those precedents are not normally investigated in depth. While marketing management plays a key role in sustainably competitive advantages, practitioners require a clear understanding of its precedents in order to implement this concept. This paper argues that marketing management, both as a culture and a behavior, cannot be manifested without firm integration not only by top management, employees, $\mathrm{R} \& \mathrm{D}$ and marketing planning department but also by all customers. One way of achieving such integration is the application of marketing knowledge management (MKM).

According to MKM literatures, this paper argues that MKM practices not only have positive relationships with firm operational and financial performance directly but also influence sustainably competitive advantages which are in turn related to bank performance. So the following questions may arise: whether marketing knowledge management influences aspects sustainably competitive advantages of firm directly? What are the key factors that would be affected by marketing knowledge management activities which would result in sustainably competitive advantages of firm? The paper introduces a new perspective of the associations and interactions that take place between marketing and knowledge management concepts which affect organizations' marketing endeavors. While such perspective is considerably new and relevant to general marketing and knowledge management literature, the fact that it focus on marketing knowledge management increases to its originality. Only a modest amount of research has been conducted on marketing knowledge management in the Iranian banking industry. Strictly, Iranian commercial banks should convert marketing knowledge management as a strategy into their core operations and systems to meet marketing and knowledge management and the bank goals. Building on the above, the purpose of this paper is to provide a model to explore the explaining effect by organizational strategies, culture and performance of senior manager, information technology, research and development, internal customer, external customer over Mellat banks' marketing knowledge management. While testing the direct effect of marketing knowledge management over sustainable competitive advantage, the proposed model builds to explore the interactions between marketing knowledge management and sustainable competitive advantage of customer, market and financial.

\section{Literature review}

According to popular belief the concept of the marketing knowledge management that has spread during the last two decades explains how merger of marketing, management, and knowledge and them completion would be practical, but in reality given its attitude towards environmental opportunities it could be claimed that marketing knowledge management is a process based on three areas of marketing management, knowledge management and marketing knowledge, and further it focuses on gaining sustainable competitive advantage and introducing all the related issues through the point of market, knowledge and management study as a basic and principle concept. Another point of view, some experts such as Michael porter, Christensen, Fahey, Lynch, Reed and Defillippi believed that all organizations should obtain sustainable competitive advantage so that they can be secured from catastrophic environmental changes and continue being compatible with environmental requirements as well. So, this paper studies the relation between MKM and SCA in three areas consisting of market, customer and finance. In the following each of these concepts are discussed.

\subsection{Marketing management}

Background of marketing management can be traced back to the starting of the work of Hoyt (1912) and White (1927), in their research on marketing management. The work of Hoyt and White attempted to introduce scientific principles to the function of buying and selling activities and provide the 
foundation for marketing management. Marketing management became more prominent in the corporate planning and strategy process by pioneering companies. Marketing as a discipline has included a number of different theoretical perspectives from domains as diverse as organizational theory, systems analysis, economics, psychology, sociology and anthropology (Buvik, 2001; MurgoloPoore et al., 2003).

Today, marketing concepts and methods are mostly used in the decision perspectives of other business functions. Dennis and Michael (2014) explained marketing as the science about management of the commodity-money relations in society integrates such major groups as quality of life, security of production and consumption, human values, ecology environment, and social responsibility. In other words, marketing management is a comprehensive assessment of the quality and quantity of distribution, promotion and positioning of goods, services and ideas in the society with the mission and the budget of each party's market turnover. Due to the limited availability of both tangible and intangible resources of the efficiency of the marketing management of any company depends not only on improving the performance of total costs, cost of production, but also on finding hidden reserves (Abishovna, 2014). Marketing is also the source of insight about the market, customers, competitors, and the business environment in general. Marketing must be a major organizational thrust, not just a responsibility assigned to a single functional department.

\subsection{Knowledge Management}

Knowledge management is an emerging concept in the field of management and no agreement has been reached on the exact nature of knowledge management (Alavi \& Leidner, 2001; Tsai \& Shih, 2004; Akroush, 2006; Bruton et al., 2007; Darvisha et al., 2008). It has been viewed as intellectual assets management, infrastructure, and customer relationship management and so. Knowledge management involves the creation, capturing, sharing, implementing and exploitation of knowledge. Knowledge management is referred to manage the corporation's knowledge through a specified process for acquiring, organizing, sustaining, applying, sharing and renewing the knowledge of employees to enhance organizational performance and create value. KM is defined as the creation, extraction, transformation and storage of the correct knowledge and information in order to design better policy, modify action and deliver results for both the employees and organizations in the life insurance business (Bruton et al., 2007). The knowledge management is to congregate, classify, store, and spread all knowledge that is required to grow and flourish the organization. Malek (2005) showed knowledge management proposed process consists of four stages; 1 ) the proactive acquisition and generation of new information, and the sensing of trends, opportunities and problems, 2) the conceptualization of new challenges and ideas, 3 ) the development and optimization of new solutions, 4) the implementation of the new solutions. According to one definition, "Knowledge management is the processes of discovery, achievement, develop occurrence, maintenance, sharing, evaluation and using appropriate knowledge in appropriate time by appropriate person in an organization that occurs through connecting human resources, information technology and communications and producing an appropriate structure to achieve organizational goals". Hence, the number of definitions of the terms knowledge management is almost as large as the number of authors inscribing to the field. However, it is essential for any research focusing knowledge management to provide a relevant definition of knowledge management appropriate to the research purpose. The most widely employed definition of knowledge is that it is something where a belief is justifiable as truth due to systematic analysis (Grant, 1996). Knowledge management effectively can provide businesses with several competitive advantages, including service quality improvement, cost and time reductions and so on. It is promoted as an essential cornerstone for companies to develop sustainable competitive advantage. In fact, it has been argued that knowledge management is the most critical element of a business's competitive success (Spender \& Grant, 1996). There is substantial evidence to support the salience of knowledge management as a source of competitive advantage (McEvily \& Chakravarthy, 2002; Bruton et al., 2007). Interest in KM has grown dramatically in the recent years, as more researchers and practitioners have become aware of the 
knowledge potential to drive innovation and improve performance. The activities of knowledge management (KM) should enable the creation, communication, and application of knowledge; and they should drive the capability of creating and adding a greater value to the core business competencies.

\subsection{Marketing Knowledge}

Today is not like yesterday, and tomorrow will be different. Continuing today's strategy is turning to a modern strategy. Tomorrow's successful companies will have to develop and implement the marketing. Goods and services have become knowledge-based and knowledge is the key to competitive benefit achievement. In organizations, marketing knowledge should enable the creation, communication, and application of knowledge and so drive the capability of creating and adding a greater value to the core business competencies. One can classify knowledge marketing into a perspective, incessantly collecting and analyzing information concerning market and the competitive environment, costumer and employee. Then a detailed study of explicit and implicit needs of internal and external customers and competitors activity. And also ask, what is the problems faced organization? Who should be the staff? Who should be the costumer? What are the competitors in the target market? To which extent the rival companies meet customer needs? In general, marketing knowledge analyzes the reliability of the chosen strategies, given the expansion of the market, advertising campaigns, and image development services and creates positive public opinion.

\subsection{Marketing Knowledge Management (MKM)}

Marketing Knowledge Management (MKM) is an emerging concept in the field of management and marketing adopted in organizations for enhancing sustainable competitive advantage (SCA). It is promoted as an essential cornerstone for companies to develop SCA and to remain at the forefront in a market. MKM is the acting of managing knowledge and marketing in market. Undoubtedly, it can argue that MKM is one of the most critical elements of a business's competitive success. Interest in MKM has grown dramatically in the recent years, as more researchers and practitioners have become aware of the knowledge potential to drive innovation and improve performance. We could define MKM as a discipline with the objectives of promoting knowledge growth, knowledge exchange, and marketing knowledge preservation within an organization in order to achieve a better exploitation of this essential resource. Akroush and Al-Mohammad (2010) stated that MKM is "a discipline that involves the recognition and analysis of obtainable and required marketing related knowledge assets and capabilities, and the ensuing planning and control of actions to develop both the marketing assets and capabilities so as to fulfill organizational objectives". They introduced different definitions to describe both marketing assets and marketing capabilities. Marketing assets defined as resource endowments of the organization has acquired or built over time and what can be deployed to advantage in the marketplace. Marketing capabilities are defined as complex bundles of skills and accumulated knowledge, exercised through organizational processes that enable organization to coordinate activities and make use of their assets. Moustaghfir (2008) believed organizational knowledge assets have been identified as sources of competitive advantage. Organizations should understand how they impact on performance in order to effectively manage these assets. Effective management of knowledge asset enhances the value of organizational competencies, which in turn support organizational processes, products and services. Faraji (2011) believes application of MKM can decrease a errors and duplication, increases speed of problem solving and decision making has following reduce costs and will be lead to more effective relationships and better services to customers and will include staffs satisfaction. Kheiri et al. (2011) stated organizations identify their capabilities and limitations, allocate sufficient resources, evaluate their abilities and finally design and develop long-term strategies by MKM. It would assist managers to identify barriers and potential assisting factors on one hand and to select feasible methods on the other hand, which will determine their future steps toward achieving highest expecting yield. Veismoradi et al. (2013) express increasing importance of MKM in the success of today's organizations is necessary need to of the modern organizations for application MKM as a major source of competitive 
success. Such a variety of marketing activities requires the existence and optimization relevant assets and growth abilities of MKM to achieve organizational goals. In research background, Kheiri et al. (2012) paid to Impact of marketing knowledge management on organizational performance (with respect to Pharmaceutical Organizations) and found that knowledge management marketing can impact on organizational performance. Hou and Chien (2010) paid to the effect of Knowledge-based activity on business performance and found that MKM can impact on organizational performance. Faraji (2011) paid to the effect of MKM on enterprises performance in banking industry of Iran and showed that it can impact on enterprises performance. Akroush and Al-Mohammad (2010) paid to the effect of MKM on performance in Jordan Telecommunication Company and showed that it can impact on performance of Telecommunication Company. Batter et al. (2008) paid to Knowledge-based capabilities and their impact on performance and showed that Successful companies are configurations of management practices that enable the development of knowledge-based capabilities. Akroush (2006) paid to the effect of Knowledge-based assets and capabilities on performance banks in Jordan and showed that they can indirect influence on Business performance. Tsai and Shih (2004) paid to the impact of knowledge-based capabilities among managers on marketing capabilities and business performance and found that they can impact on organizational performance. It has to be acknowledged that reaching a MKM has been a matter of significance to an organization. According to literature review, experts' views, and exploratory factor analysis on the subject, the components of MKM have been classified into six categories comprised of organizational strategies, culture and Performance of Senior Manager, information technology (IT), research and development (R \& D), internal customer (personnel), external customer (client) and then have been fairly surveyed more.

\subsubsection{Organizational strategy (OS)}

The core impact of marketing is to proportionate strategic decisions in the area of products, promotion, place distribution, pricing, packaging, presentation, public relation, power competitors, people, participation, probe market, physical evidence, process (13Ps marketing) to achieve the obligation and mission of an organization. It must introduce a president or a special department for marketing strategy, or a coordinating center responsible for continuous improvement of the marketing activity. The strategic decisions directly affect all marketing activities for implementing the marketing strategy. The marketing strategist activities and abilities may be too weak to support the operations of the marketing system. Marketing strategies must confront the difficulty of implementing mentioned activities and consider them roles of in the organization' management infrastructure. Therefore, it is valuable to explore the connection between the gaps marketing activities and mistakes strategist performance, which consists of productivity, cost performance, competitiveness, sales growth, profitability, market share and innovativeness, was used to measure corporate performance (Choi \& Lee, 2003; Madu et al., 1996, Lin \& Tseng, 2005). Successful organizations adapt their marketing strategies to market changes. Boundary spanners, such as marketing strategist, because they are able to embed themselves in social networks outside the organization, play a key role in developing market knowledge. However, if this knowledge remains solely with the boundary spanners, it cannot be used effectively to improve firm performance. The principle of the strategic orientation includes strategic objective market analysis. Strategic orientations presupposes justification of an attractive segment for the size, growth, intensity of competition, possible profit and meet current and potential resources of the firm. The marketing process is the activities aimed at finding and expertise and methods of high-quality work, their estimate of the synergies in the development of relevant today as they were centuries ago.

\subsubsection{Culture and Performance of Senior Manager ( $C \& P S M)$}

The culture is patterns, historical, includes ideas, values, selective, learned and is a product of behavior. In the late 1960s in the field of trade culture, the study of culture focused exclusively on understanding consumer behavior, the definition of cultures and subcultures as market segments, culture as communication, and cultural comparisons of international markets. The culture can declare as a pattern 
of beliefs and expectations shared by organization members. We define organizational culture as the pattern of shared values help individuals understand organizational functioning and thus provide them norms for behavior in the organization. Organizational culture includes ethics, values, beliefs, attitudes, norms, ethos, climate, environment, and culture. Researchers suggested that greater attention be paid to organizational culture along with structural explanations for managerial effectiveness. They recognize the importance of organizational culture in the management of the marketing function. That is, organizational culture is related to the causality that behavior of managers to organizational functioning. On the other hands, knowledge is rapidly becoming a very important measure of the company's future performance (Choi \& Lee, 2002), it is therefore vital that Knowledge indictors and measure are developed by senior management in order to promote organizational culture related with competitors, customers, and employees. In fact marketing activity lies at the core of leading and managing a business. It provides the focus for interfacing with customers, staffs and competitors.

\subsubsection{Information technology (IT)}

Rapid development of the information technology has pushed the world into the era of a new communications. In addition, with the revolution of information technology, the value of knowledge assets and capabilities has been greatly enhanced. Armistead and Meakins (2002) argue that the creation of business value mainly comes from intangible assets, such as knowledge and IT (Lin \& Tseng, 2005). As well as marketing activity is performed at maximum potential through the use of advances in IT and knowledge management. These days, a tremendous change is seen on business units through implementation of IT equipment. The recent advances on technology have revolutionized IT and people start creating new ideas based on these advances. The results confirm that both knowledge management and IT influence dynamic organizational skills (Darvisha et al., 2013). IT processes can the creation of knowledge and the conversion of products and services through knowledge management. The most basic feature of modern organizations emphasize on knowledge and IT. Unlike previous, organizations advanced technologies today, require acquisition, management and exploitation of knowledge and information to improve efficiency, manage and track variations are endless. Knowledge is a powerful tool that can change the world and innovations made possible. Knowledge management is an inter disciplinary business model with all aspects of knowledge creation, Coding, sharing and using knowledge to enhance learning and innovation in the context of the company and is working (Meihami \& Meihami, 2014)

\subsubsection{Research and development $(R \& D)$}

In today's competitive environment, the companies that succeed will be those which develop products that satisfy customer needs better than the products of their competitors. Therefore, it is necessary that companies fully research such needs, and generate ideas and solutions that can best satisfy them. Gupta et al. (1986) developed a theoretical framework for the study of R\&D marketing integration. The marketing supplies the voice of the customer, while research and development (R\&D) uses the company's assets and capabilities to create a product with a competitive advantage (Song \& Thieme, 2006). It is emphasized the greater is the need to integrate marketing and R\&D functions within the company. However, although the need for integration has been widely recognized, the levels of integration of $R \& D$ and marketing in practice have proven to be low. Marketing researchers see R\&D as a subordinate function and the $R \& D$ handles marketing as a static or even limited function. They have put forward a theoretical framework for the study of R\&D - marketing integration and other authors such as 1 and 7 have defined different integrative mechanisms that should lead to higher levels of R\&D - marketing integration. The rationale for this model is based on three main concepts: The degree of R\&D - marketing integration required depends on company's new product strategy and its perceived environmental uncertainty. The company's ability to achieve R\&D - marketing integration is affected by its (1) organizational factors such as structure and reward systems and (2) socio-cultural differences between $\mathrm{R} \& \mathrm{D}$ and marketing managers. The integration gap that results from the difference between the perceived need and achieved integration is expected to affect the NPD success of the 
company. There are gaps that hinder the integration process of marketing and R\&D and surely knowledge management can fill these gaps. The degree of integration achieved was assessed by conducting a questionnaire (Fain et al., 2011).

\subsubsection{Internal Customer (personnel)}

Now this concept that human capital is critical for the success of any organization is totally stabilized as organizations realized. It is important that lack of commitment from employees can be harmful to an organization, resulting in poorer performance arising from inferior service offerings and higher costs. Hence, lack of employees commitment, and citizenship behavior, might negatively affect an organization's market orientation. Accordingly, for Jordanian banks to succeed in their market-oriented endeavors, employees' commitment must be guaranteed. One way of achieving such commitment is the application of internal marketing programs (Farzad et al., 2008). Internal marketing is very important in service sector where the only way to promote business is through staff. Especially in service sector the quality of service mainly depends on employees because service providing companies do not have physical goods. Internal marketing is an equal handling of both employees and customers with the aid of proactive polices to reach organizational objectives. In service sector, the significance of staff is obvious; if staff provides better services the customer will be more and more satisfied. But customer satisfaction only results when staff of an organization is satisfied. "Payne argues that the main aims of internal marketing are the development of internal and external customer awareness and the removal of functional barriers to achieve organizational effectiveness. Employee retention is major vital issue facing corporate leaders as a consequence of the lack of skilled labor, economic growth and employee turnover. Retention is defined as the ability to hold onto those employees you want to keep, for longer than your competitors. (The Effect of Internal Marketing on Employee retention in Pakistani Banks). Schultz also mentioned that Internal marketing (IM) is a pre-requisite for employee satisfaction. Lambert suggested that committed employees demonstrate higher job performance. Internal marketing enhances the correct performance of knowledge management and can be used as a learning and knowledge management enrichment.

\subsubsection{External Customer (client)}

In modern conditions it is impossible to obtain positive results of marketing activities without assessing public opinion, and without the participation of society in social actions. Therefore, the effectiveness of marketing management is the integrating function, which reflects the relationship between the developed strategies, the use of elements of marketing, operational implementation of programs in the areas and social and corporate responsibility for the results of the work to the public. For a long period of time, Marketing activities were only limited to external customers for sales inducements. And the central piece of all those activities was to retain customer more and more. The justification for customer retention was very much obvious i.e. customer retention leads a customer to customer loyalty and loyal customer are less sensitive to price; giving a firm an option for better profitability. It was found that three of customer service skills components, namely; reputation building skills, nonverbal communication skills, and customer service culture have positive relationships with customer service satisfaction dimensions (overall, functional, and technical customer satisfaction). Also, overall customer service satisfaction and technical customer service satisfaction dimensions fully mediated the relationships between customer service skills and customer loyalty. For this reason, the book emphasizes the role of marketing in creating value for customers this leads to the creation of value for other firm stakeholders, including shareholders and employees.

\subsection{Competitive Advantage}

Although there are many different viewpoints between the discussed theory to reach SCA, they are all similar in one way which their aim is to maximize the organizational competitive advantage and improve the organization's position among their competitors. It has been a long disputation about how organizations could reach to sustainable competitive advantage. Also many experts have revealed their 
opinions for such a matter including porter which believed that cheap labors and natural resources are not good economy requirements (porter 1985 sited by Andersen, 2013). He expressed that a competitive advantage is the ability which is obtained through resources and attributes that helps a firm to perform at a higher level than the other competitors in the same industry or market (Chacarbaghi \& Lynch, 1999 sited by Josiah, 2013). When a firm has reached a competitive advantage and prevents imitation by competitors, resisting erosion by competitor behavior and achieving sustainable competitive advantage is considered as an obvious result. However preventing imitation is not permanent; the firm should make any effort to delay this occurrence to gain the maximum benefit from its competitive advantage (Reed \& Defillippi, 1990; Pearce \& Robinson, 2000; Christensen, 2001; Chunxia, 2012). Barney argued that a firm has a competitive advantage when it implies a value creating strategy while any current or potential competitors are deprived to implement the strategy simultaneously and they are also not capable of duplicating that (Barney, 2000). Lippman and Rumelt (1982) stated that a firm competitive advantage is assumed as a sustainable paradigm as long as competitors are unable to duplicate it, in this sense it wouldn't last if they become aware of how they can imitate it. It has to be noted that industry type has a significant effect on a period of calendar time that a firm enjoys a concept of sustained competitive advantage so that sustainability lasts longer in high-tech industry than other Industries.

In 1990, Prahalad and Hamel reported that Western and Japanese companies try to standardize product cost and quality. Although this competency could be considered as an option to a firm, today it is not dramatically emphasized as a real source to gain a competitive advantage. In other words cost and quality cannot be ignored as an enabler to a firm to overcome competitors such that it could derive competitive advantage. Surveys conducted by Prahalad and Hamel (1990) performed to identify whether a service quality of Pakistan telecom results to a firm competitive advantage absorbing customers and becoming a sustainable competitive advantage through a period of time. The study demonstrated that the telecom industry has a low rating on empathy, personal attention to customers and understanding their needs. The question of what leads to a successful business is not only about today's economic crisis, but also is a question that each company should follow to find a fairly feasible answer (Oliver, 2000). In 2001, Zook and Allen argued that having a profitable and differentiated company obtained through some source of competitive advantage is extremely required to make a sustained and profitable growth. According to Reed and Defillippi (1990) the sources of competitive advantage are as numerous as firm activities. A survey including a study of 59 articles in 8 fields (strategic management, strategic management of marketing, marketing management, information technology, knowledge management, resources-based theory, entrepreneurship, and human resource management) demonstrated that among Porter's triple strategies, the strategy of differentiation has captured highest attention (Hamidizadeh \& Taheri, 2013). A successful company should focus on its core competence and invests in development of activities creating value and reaches core competence that is the source of comtetive advantage. Core competence is considered as a fundamental concept for competitive strategy in a highly competitive market which is identified as knowledge set helping a company to perform in a different way from competitors and results in a competitive advantage. The core competence concept has been implemented to an organization identifying and efficiently utilizing its strength. Gupta et al. (2009) further argued that core competence is a collection comprised of communication, involvement and a deep commitment across organizational boundaries. Ljungquist (2008) demonstrated that core competence has been emerged to justify business diversity at large companies and provide support for some internal processes including product development. In 1990, Prahalad and Hamel introduced companies' ability as a real source of competitive advantage empowering business to overcome competitors through rapidly changing environment by consolidating technologies and production skills into competence. It has to be emphasized that a firm could reach sustainable competitive advantage if it enjoys having rare, unique and none-replaceable resources. Gupta et al., (2009) point out these resources are not generally capable of creating a competitive advantage which is in higher level than others. A company needs to answer the question of how it can use available sources and how to create new resources and finds a new approach to develop a new type 
of product and finally these resources which are considered as a special form of final products and services should create a competitive advantage to a firm and should contribute to the firm's value creation. Surveys such as that conducted by Holliday (2001) shows that sources of firm's competitive advantage should be supported by human factors. According to his argument, social barriers including organizational classes, knowledge management, leadership styles, work teams and etch, have a more considerable impact on effective use of the sources than even strategic barriers. Leadership is a most effective component of a companies' competitive advantage that should not be ignored easily (White $\&$ Moraschinelli, 2009). In other words there is not any other entity with such an important effect and influence on the management (Burns, 2008). Trung (2014) believed that a strategic position of a companies' management is foreseeing the market trend and obtaining sustainable competitive advantage to improve companies' position among competitors.

\subsubsection{Ensuring of competitive advantage}

In some cases it is impossible for competitors to imitate however it is quite rare. Physically unique resources made by human resource through their ability are good examples in such a case (Pearce \& Robinson, 2000); but imitation is one of the most challenging issues for an organization trying to sustain a competitive advantage. Therefore a firm should invest on raising a barrier to imitation in order to ensure sustainability of competitive advantage. Although it is inevitable that a competitive advantage is not quite sustainable by itself and finally competitors can find a way to realize how they can imitate the strategy using by the firm (Christensen, 2001). However there is no insuperable barrier to imitation, an organization has to prolong the competitive advantage with emphasis on two proposed strategies as follow. First, organizations should make their effort to not let competitors comprehend the foundation of their strategy and realize how they create the competitive advantage. Second strategy is to use an array of activities instead of using a single activity. This means matching an array of interlocked activity and making an ambiguous strategy to implement which is harder for the competitors to duplicate. As this approach reduces the probability of competitors' imitation, it may ensure the competitive advantage.

\subsubsection{Sustainable competitive advantage}

It has to be acknowledged that reaching a competitive advantage has been a matter of significance to an organization since before and much attention has been paid to this issue by a wide range of experts and specialists. It may be said a most important subject in a competitive advantage concept is the question of what are the possible signs of a competitive advantage; in other words what are the measures showing that a company has reached a competitive advantage. According to literature review and experts views on the subject, the mentioned measures have been classified into three categories comprised of market, finance and customer and then have been fairly surveyed more. A sustained competitive advantage is obtained through unique values which are creating a strategy that any other current or potential competitor is unable to imitate or imply it simultaneously and finally the using strategy cannot be duplicated for long period of time.

\subsubsection{Customer}

A core competence which is defined as a skill enabling an organization to create a fundamental value and leads to customer loyalty should result to customer perceived value. Studies show that customer loyalty and customer attention are two challenging concepts that all organizations encounter. It is exactly clear that loyal customers can raise sales and customer share and reduce costs and higher prices (Alrubaiee \& Alnazer, 2010). As a result our study seeks to address two critical dimension of competitive advantage with focus on customers, including flexibility and responsiveness. Flexibility refers to organization capabilities to provide a superior customer value (Johnson et al., 2008) and responsiveness is defined as an organization ability to respond fast to their customers' wants and needs 
(Carlos et al., 2010). A competitive advantage can be obtained through meeting organizational goals and customer needs in a highly competitive environment (Evans et al., 2006). Therefor organizations should fight against each other for capturing customer attention and making a loyal customer. In other words a competitive advantage is reached when customer needs and wants are met more effective and efficient than competitors for a long time by a company, however their competitors make attempt to duplicate, reproduce and even surpass the competitive advantage.

\subsubsection{Market}

In 2010 a study conducted by li and Zhou (2010) to investigate how market orientation and managerial tie can impact competitive advantage. This research showed that one of the most important dimensions of a firm's competitive advantage is institutional advantage which means an organization's superiority in obtaining rare sources and institutional support. In this context it is stated that brands and corporate images have a significant impact on sustained competitive advantage required for a highly competitive environment (Seetharaman et al., 2001; Amini, 2012).

\subsubsection{Finance}

Reaching a competitive advantage results to a position for a company due to which it can achieve and sustain above average profitability for some years (Jones \& Hill, 2013). It has to be noted that a profit is gained through sales incomes results from customer purchase (Rijamampianina et al., 2003; Thompson et al., 2012).

\section{Research model and hypotheses}

The relationships among MKM and factors of SCA are discussed and hypotheses related to these variables are developed. Their search framework generated in this study is illustrated in Fig. 1. This framework briefly proposes that the six different items of MKM in the banking industry will enhance its SCA. It examines what types of components are most crucial to be converted into competitive advantage through MKM, describes and understands factors of SCA and also determines relationship between MKM and SCA in the banking industry of Iran. So this paper proposes three following hypotheses.

Hypothesis1. Marketing knowledge management (MKM) is positively associated with Market centered sustainable competitive advantage (MSCA).

Hypothesis2. Marketing knowledge management (MKM) is positively associated with customer centered sustainable competitive advantage (CSCA).

Hypothesis3. Marketing knowledge management (MKM) is positively associated with financial centered sustainable competitive advantage (FSCA).

\section{Methodology}

In this section, the sample, procedures of data collection, operational measures of variables and statistical analyses are studied in order to determine the links between dynamic capabilities and sustainable competitive advantage.

\subsection{Sample and procedures}

The banking industry is a major part of Iran's economy. After study of the performance statistics and information of Iranian banks, the interviews were conducted with expert academics in the banking industry and 50 of the deputy and directors of Iran banks. After all statistical studies and discussions, Mellat Bank was chosen as case study because of the implement of appropriate strategies in maintains and enhance of its competitive advantage among other Iranian banks. The research has been shown 
MBI has reached to find the competitive advantage among their competitors in recent years. For this reason, this research attempts investigate this practical success in the context of scientific study. Following the investigations conducted different strategies lead to achieve these advantages. One of the most important strategies is MKM and its implementation in the Mellat bank. MBI has the considerable growth in the competition with rival, turned a suitable locale for research to examine the influence of MKM on SCA in the banking industry.

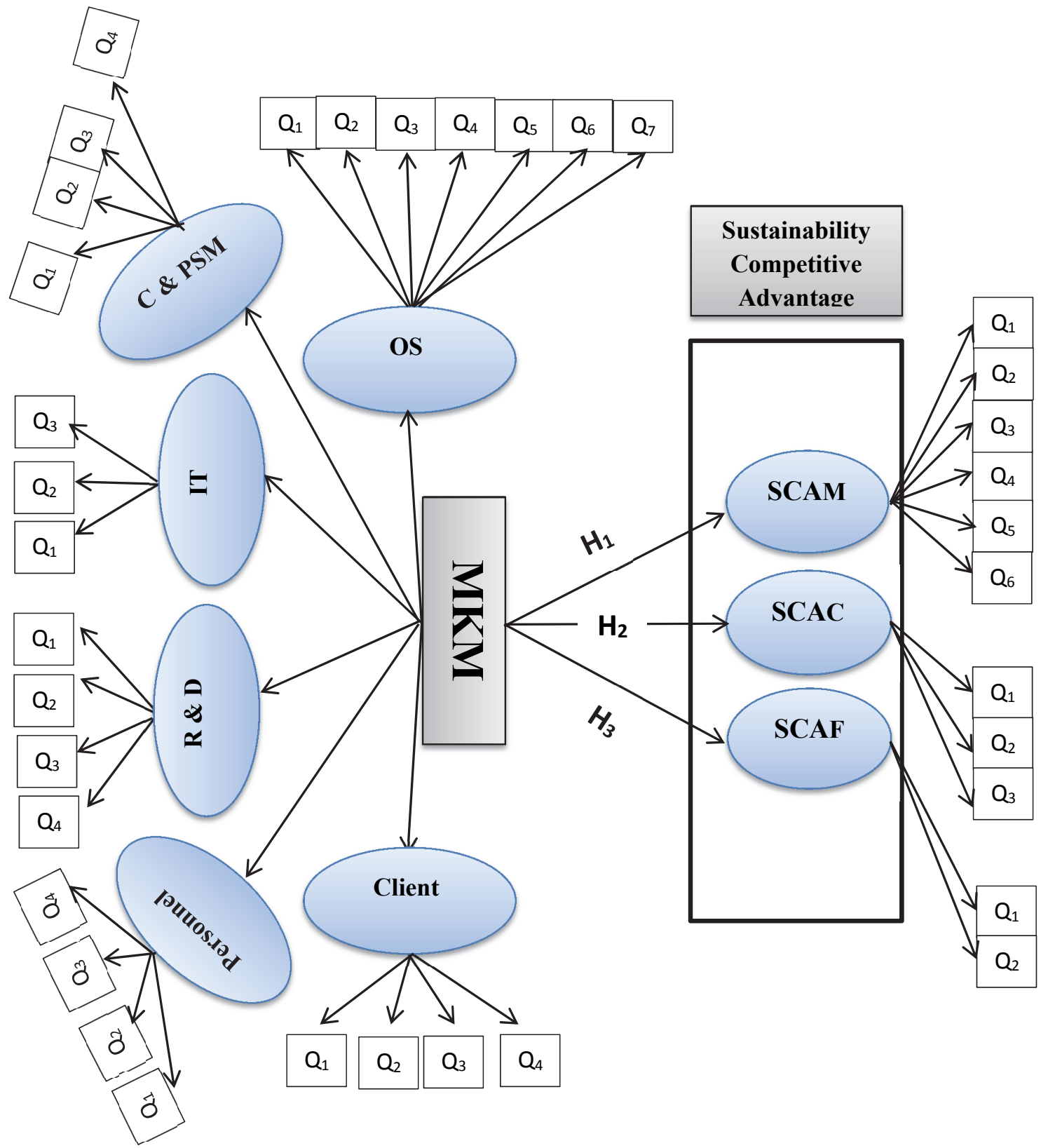

Fig. 1. Conceptual model between MKM and SCA

As an effort to ascertain the content validity of the survey questionnaire, a draft survey was pre-tested by both academicians (i.e. two Strategic Management Assistant Professor) and practitioners (i.e. ten managers' Bank). The participants were requested to evaluate the survey questionnaire on its wording, clarity and relevancy. Ultimately, the final version of questionnaire was distributed randomly to those who are in the executive or Senior Managers, specialists and consultants from the administration and 
improvement methods, marketing, strategy, risk management and operations manager department of MBI. The reason of choosing this group of professionals as the unit for analysis is because they are the most knowledgeable in terms of the research issues of the study.

From the total of 150 questionnaires circulated, 122 were returned with complete answers, which represent a response rate of $81.3 \%$. The number of valid and usable questionnaires was 101 . The Fig. 2 shows the company characteristics and the target respondents. The Fig. 2 shows that the majority of Respondents, 81.1 percent, are males that are consistent with the Iranian society which is still relatively a male dominated especially on the top management positions. The majority of managers are middleaged and well educated. This is consistent with the Iranian society that is described as Middle-aged and enjoys high levels of education in the bank department. Being well educated would greatly help MBI in building and accumulating MKM to reach SCA now and in the future. Also, the Fig. 2 shows that the majority of managers, 67 percent, is well experienced in this industry and has more than ten years of experience. This holds a strategic implication that indicates that MBI has relevant and sufficient business industry experience that is crucial for building and sustaining assets and capabilities as a source of competitive advantage for a long time. Finally, the Fig. 2 shows that 61.6 percent of managers have business education background which indicates there is reasonable recruitment process in the bank that focus on quality of people as one of their major assets to achieve a success. The part of measure is organized into two sections that present how to measure the dimension of each construct. It should be mentioned, in order to assess the precision and focuses of the respondents, some questions were designed negatively.
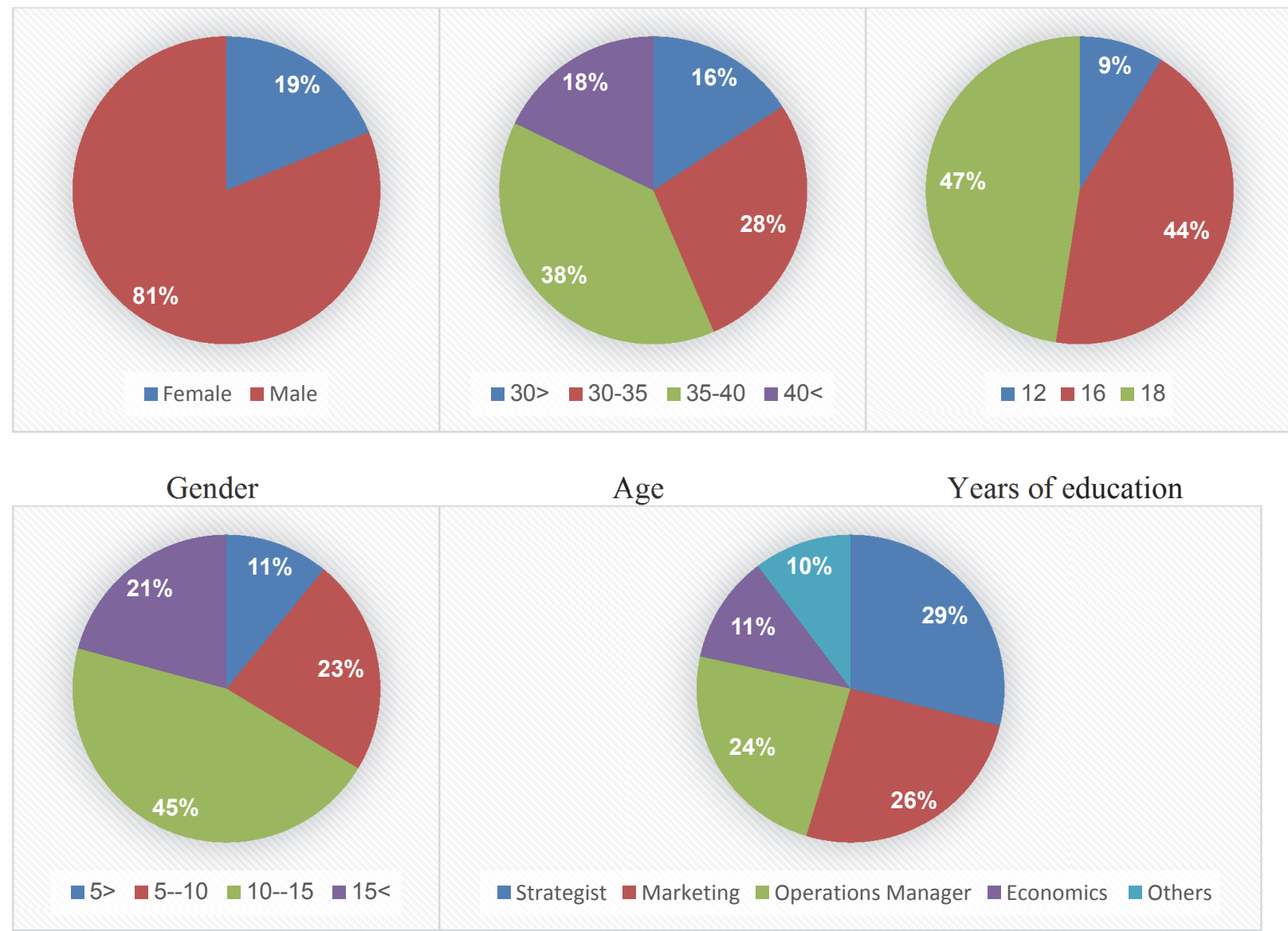

Job experience

Educational background

Fig. 2. Personal characteristics of the participants 


\subsection{Measure of MKM}

Six MKM dimensions including: organizational strategies, culture and Performance of Senior Manager, information technology (IT), research and development (R \& D), internal customer (personnel), external customer (client) focus were evaluated in this study. These MKM dimensions were selected based on the studies of literature and techniques of exploratory factor analysis. Each of these MKM practices was measured via a five-item, 5-point Likert scale ranging from strongly disagree $=1$ to strongly agree $=5$. The construction of MKM in this study is measured as a whole, with the construct itself made out of the six dimensions organizational strategies, culture and performance of senior manager, IT, R \& D, personnel, and client.

\subsection{Measure of SCA}

The instrument of SCA has been used to assess SCA across various competitive advantage settings. Thus the three area of SCA were chosen to represent the SCA dimensions in the present study as a result. A review of the literature concerning the sustainable competitive advantage in service institutions such as banks found that most research assessed the construct of service institutions from the market, costumer and finance perspective. Each of these SCA practices was separately measured and analysis. In order to measure respondents' perception towards the SCA within bank, a 5-point Likert scale was developed $(1=$ strongly disagree; $5=$ strongly agree $)$.

\subsection{Statistical data analysis}

Exploratory Factor Analysis (EFA), Confirmatory Factor Analysis (CFA), and a Structural Equation Modelling (SEM), were used on the multi-item measure in this study. In order to perform the SEM technique, the data analysis was performed in five steps: first is check of normality assumption, second is to examine the KMO and Bartlett's test, third, is to perform the exploratory factor analysis, forth, is to carry out the confirmatory factor analysis and finally, is examining the hypotheses through SEM. In the following, each of the steps is described and analyzed.

Step 1: One of the main functions includes checking multivariate normality to determine if a data set is well modelled by a normal distribution. Normality test was achieved through skewness $< \pm 2$ and kurtosis $< \pm 2$. In This study, the amounts of skewness and kurtosis were the ranges. Furthermore, the Shapiro-Wilks tests were also used to verify the existence of normality. The test revealed the normal distribution of the data since the $\mathrm{p}$-value is greater than 0.05 . The $\mathrm{p}$-value in this study is more than 0.05 and thus can assume that the model satisfactorily fits a normality distribution (Razali \& Wah, 2011)

Step 2: In the section, the Kaiser-Meyer-Olkin (KMO) and Bartlett's Tests being carried out to establish the correlations among variables. The KMO measures of sampling adequacy tests whether the partial correlations among variables are small. Another indicator of the strength of the relationship among variables is Bartlett's test of Sphericity. The KMO measures the sampling adequacy which should be greater than 0.5 for a satisfactory factor analysis to proceed. Looking at the Table 1 and Table 2, the KMO measure is 0.794 and 0.820 for MKM and SCA, respectively. Large values for the KMO measure indicate that a factor analysis of the variables is a good idea. From the same table, we can see that the Bartlett's test of Sphericity is 0.000 . This means that the correlation matrix is not an identity matrix. It is concluded that the relationship among variables is strong. It is a good idea to proceed a factor analysis for the data.

Step 3: In order to separate the dimensions of each construct, exploratory factor analysis (EFA) with varimax rotation was performed separately on MKM and SCA factors. In the course of the validation process, three and nine items (3 items from SCA and 9 items from MKM factors) were found to have unacceptably low factor loadings of less than 0.5 on their respective unobserved hypothetical or latent variable which were subsequently removed. The internal reliability is evaluated of scales by Cronbach's 
alpha $(\mathrm{C}-\alpha)$. The result has shown that the Cronbach's alpha value ranges between 0.762 to 0.922 for MKM factors, 0.844 for SCA of market entered, 0.777 SCA of customer centered and 0.717 for financial centered indicating the measurement of the variables are well above the acceptable threshold of 0.70 according to Nunnally and Bernstein (1994).

\section{Table 1}

Results of CFA and internal reliability testing \& $\mathrm{K}-\mathrm{M}-\mathrm{O}$ measure

\begin{tabular}{|c|c|c|c|c|c|c|}
\hline Factor & Mean & SD & Lading & AVE & $\mathrm{CR}$ & $\mathrm{C}-\alpha$ \\
\hline Factor 1 & & & & 0.51 & 0.85 & 0.7998 \\
\hline To make plans and strategic decisions and programs & 3.78 & 0.903 & 0.67 & & & \\
\hline $\begin{array}{l}\text { To detect two factors including latent needs and market environmental } \\
\text { changes, and also to be able to respond them }\end{array}$ & 3.21 & 0.942 & 0.81 & & & \\
\hline $\begin{array}{l}\text { Efficiently has used marketing performance such as market orientation } \\
\text { and service quality }\end{array}$ & 3.48 & 0.961 & 0.77 & & & \\
\hline $\begin{array}{l}\text { To fully analyze the external environment and process information as } \\
\text { well }\end{array}$ & 3.04 & 0.923 & 0.76 & & & \\
\hline $\begin{array}{l}\text { To analyze the competitors and make a network competition based on } \\
\text { cooperation }\end{array}$ & 3.12 & 0.893 & 0.75 & & & \\
\hline $\begin{array}{l}\text { Ability to make, keep, and finally improve its relation with competitors } \\
\text { and financial and investor institutions }\end{array}$ & 3.51 & 0.945 & 0.76 & & & \\
\hline $\begin{array}{l}\text { is able to provide an appropriate distribution of new services like } \\
\text { establishing new distribution channel in some particular geographical } \\
\text { areas }\end{array}$ & 2.98 & 0.911 & 0.77 & & & \\
\hline Factor 2 & & & & 0.59 & 0.79 & 0.805 \\
\hline $\begin{array}{l}\text { is able to manage social capitals such as knowledge, culture, } \\
\text { entrepreneurship, and communication }\end{array}$ & 3.41 & 0.952 & 0.69 & & & \\
\hline does not encourage teamwork, cooperation, consultation an empathy & 3.26 & 0.924 & 0.77 & & & \\
\hline $\begin{array}{l}\text { has tried to establish commitment-based communication and mutual } \\
\text { trust in all organization levels }\end{array}$ & 3.48 & 0.937 & 0.88 & & & \\
\hline $\begin{array}{l}\text { senior management participation regarding adaptation with unexpected } \\
\text { changes is not tangible }\end{array}$ & 3.09 & 0.913 & 0.82 & & & \\
\hline Factor 3 & & & & 0.51 & 0.72 & 0.853 \\
\hline $\begin{array}{l}\text { has assumed that improvement of information and communication } \\
\text { system technology is a significant part of its programs }\end{array}$ & 3.42 & 0.946 & 0.90 & & & \\
\hline $\begin{array}{l}\text { enjoys having an information and communication technology } \\
\text { standards of banking system }\end{array}$ & 3.28 & 0.939 & 0.83 & & & \\
\hline $\begin{array}{l}\text { has provided an information and communication systems with a } \\
\text { flexible and efficient infrastructure }\end{array}$ & 3.51 & 0.908 & 0.74 & & & \\
\hline Factor 4 & & & & 0.58 & 0.69 & 0.804 \\
\hline $\begin{array}{l}\text { has the ability to fully employ equipment, systems and modern } \\
\text { technologies }\end{array}$ & 3.17 & 0.889 & 0.80 & & & \\
\hline $\begin{array}{l}\text { has innovation and creativity in the contexts of prediction, } \\
\text { standardization and reaching competitive advantage. }\end{array}$ & 3.26 & 0.963 & 0.66 & & & \\
\hline $\begin{array}{l}\text { has provided technical knowledge and easy access to competitive } \\
\text { resources as well as adaptability with new technologies }\end{array}$ & 3.85 & 0.944 & 0.82 & & & \\
\hline $\begin{array}{l}\text { has innovation and creativity in the contexts of prediction, } \\
\text { standardization and reaching competitive advantage }\end{array}$ & 3.43 & 0.938 & 0.76 & & & \\
\hline Factor 5 & & & & 0.56 & 0.76 & 0.765 \\
\hline $\begin{array}{l}\text { has involved employees who are compatible with each other and also } \\
\text { can accept the changes }\end{array}$ & 3.25 & 0.864 & 0.87 & & & \\
\hline $\begin{array}{l}\text { has provided a place in which the employee can apply their skills, } \\
\text { ideas, abilities and their individual knowledge }\end{array}$ & 3.52 & 0.885 & 0.80 & & & \\
\hline $\begin{array}{l}\text { tries to fulfill the employee needs, create satisfaction and make } \\
\text { employees feel justice }\end{array}$ & 2.98 & 0.921 & 0.76 & & & \\
\hline has provided some approaches to motivate and improve the employees & 3.04 & 0.940 & 0.77 & & & \\
\hline Factor 6 & & & & 0.63 & 0.81 & 0.872 \\
\hline $\begin{array}{l}\text { tries to communicate with customers (most particularly with key } \\
\text { customers) and makes them loyal }\end{array}$ & 3.19 & 0.904 & 0.97 & & & \\
\hline $\begin{array}{l}\text { tries to provide a superior services and handle customer needs and } \\
\text { complains }\end{array}$ & 3.37 & 0.874 & 0.72 & & & \\
\hline makes no effort to fulfill current and future need of customers & 3.09 & 0.921 & 0.74 & & & \\
\hline $\begin{array}{l}\text { tries to provide a quite polite services for customers and give them right } \\
\text { information at right time }\end{array}$ & 2.96 & 0.908 & 0.86 & & & \\
\hline
\end{tabular}

$\mathrm{K}-\mathrm{M}-\mathrm{O}$ measure of sampling adequacy $=0.794 ;$ Bartlett test of Sphericity $=957.257 ; \mathrm{p}<0.000$. 
Table 2

Results of CFA and internal reliability testing \& $\mathrm{K}-\mathrm{M}-\mathrm{O}$ measure

\begin{tabular}{|c|c|c|c|c|c|c|}
\hline Factor & Mean & SD & Lading & AVE & CR & $C-\alpha$ \\
\hline Factor 1 & & & & 0.522 & 0.874 & 0.844 \\
\hline $\begin{array}{l}\text { Integrate performances to find the highest position } \\
\text { among all competitors }\end{array}$ & 3.70 & 0.985 & 0.69 & & & \\
\hline $\begin{array}{l}\text { Focusing on market growth and market share } \\
\text { indicator }\end{array}$ & 3.75 & 0.974 & 0.73 & & & \\
\hline Successful in effective in the market & 3.42 & 1.051 & 0.84 & & & \\
\hline $\begin{array}{l}\text { Providing a socially complicated environment } \\
\text { which it is difficult for competitors to imitate }\end{array}$ & 3.58 & 0.93 & 0.71 & & & \\
\hline $\begin{array}{l}\text { Fully committing to the society and tries to create } \\
\text { value for that }\end{array}$ & 3.38 & 0.893 & 0.68 & & & \\
\hline $\begin{array}{l}\text { Integration and re-formulation of services and } \\
\text { create new services faster than competitors }\end{array}$ & 3.47 & 0.819 & 0.67 & & & \\
\hline Factor 2 & & & & 0.669 & 0.810 & 0.777 \\
\hline $\begin{array}{l}\text { Attractive offers the customers are not superior } \\
\text { compared to competitors }\end{array}$ & 3.27 & 1.067 & 0.66 & & & \\
\hline $\begin{array}{l}\text { Providing efficient services with quality and } \\
\text { flexibility }\end{array}$ & 3.32 & 1.104 & 0.92 & & & \\
\hline $\begin{array}{l}\text { Investing in customer loyalty and satisfaction and } \\
\text { create a positive impression }\end{array}$ & 3.03 & 1.118 & 0.85 & & & \\
\hline Factor 3 & & & & 0.639 & 0.811 & 0.717 \\
\hline $\begin{array}{l}\text { Attractive offers the customers are not superior } \\
\text { compared to competitors }\end{array}$ & 3.30 & 0.922 & 0.58 & & & \\
\hline $\begin{array}{l}\text { Providing efficient services with quality and } \\
\text { flexibility }\end{array}$ & 3.60 & 0.991 & 0.97 & & & \\
\hline
\end{tabular}

Step 4: A confirmatory factor analysis (CFA) is performed to evaluate the overall measurement model. In order to evaluate the validity of measurement model, convergent and discriminant validity were evaluated. In the model, all the factor loadings and composite reliabilities fall in the acceptable ranges and are significant at the 0.001 level. Factor loadings range from 0.59 to 1.00 and 0.52 to 0.94 , Composite reliabilities (CR) range from 0.857 to 0.955 and 0.703 to 0.851 , AVE ranges from 0.547 to 0.835 and 0.556 to 0.659 for MKM, SCA, respectively. The results show that the model meets the convergent validity criteria. Tables 1 and Table 2 show the mean, SD, factor loading, AVE, CR and C$\alpha$ of every constructs. Convergent validity can be established if two similar constructs correspond with one another, while discriminant validity applies to two dissimilar constructs that are easily differentiated. Tables 3 and 4 indicate that the measurement model has satisfactory discriminant validity. In the tables, diagonal elements in italics are the AVE and off-diagonal elements are the squared correlations between constructs. It is obvious that each diagonal element is higher than respective off-diagonal elements. Therefore, all constructs in the measurement model were judged as having adequate discriminant validity.

Step 5: Fig. 3 exemplifies the proposed structural model showing the association between the six and three dimensions of MKM and SCA, respectively. To examine the model, conventional maximum likelihood estimation approaches were used. It is assessed the measurement model fit by evaluating: (1) absolute fit indices including observed normed $\chi^{2}\left(\chi^{2} / \mathrm{df}\right)$, goodness of fit index (GFI), adjusted goodness-of-fit index (AGFI) and adjusted goodness-of-fit index (AGFI); (2) Comparative fit indices including normed fit index (NFI), and comparative fit index (CFI); and (3) parsimonious fit indices including parsimony goodness-of-fit index (PGFI) and parsimony normed fit index (PNFI) and the root 
mean square error of approximation (RMSEA). Table 5 summarized the results of CFA models, all the model-fit indices are well above their common acceptable levels in which $\chi^{2} / \mathrm{df}$ was less than 3.0 and greater than 0.90 for GFI, AGFI, CFI and NFI as suggested by Bagozzi and Yi (1988), with RMSEA less than 0.08 according to Browne and Cudeck (1993), suggesting that the CFA models fit well. In their studies, Anderson and Gerbing (1988) suggest that values greater than 0.90 are desired for GFI, CFI, AGFI, and NFI while Browne and Cudeck (1993) required values less than 0.08 for RMSEA. Based on Table 5, the ratio of $\chi^{2}$ statistics to the degree of freedom for our model was 1.762 . The value of the remaining fit indices include the GFI $=0.93$; $\mathrm{AGFI}=0.91 ; \mathrm{CFI}=0.95 ; \mathrm{NFI}=0.99$; and RMSEA $=0.068$ ). All the model-fit indices are well above their common acceptable levels, suggesting that the structural model fits well.

\section{Table 3}

Discriminant validity analysis of MKM

\begin{tabular}{lcccccc}
\hline Factor & SGM & CL & IT & R\&D & ICUS & ECUS \\
\hline SGM & 0.750 & & & & & \\
CL & 0.601 & 0.634 & & & & \\
IT & 0.548 & 0.531 & 0.592 & & & \\
R\&D & 0.434 & 0.421 & 0.403 & 0.573 & & \\
ICUS & 0.319 & 0.289 & 0.326 & 0.160 & 0.550 & \\
ECUS & 0.248 & 0.239 & 0.217 & 0.141 & 0.160 & 0.562 \\
\hline
\end{tabular}

Table 4

Discriminant validity analysis of SCA

\begin{tabular}{lccc}
\hline Factor & SCAM & SCAC & SCAF \\
\hline SCAM & 0.522 & & \\
SCAC & 0.176 & 0.669 & 0.636 \\
\hline SCAF & 0.250 & 0.231 & 0 \\
\hline
\end{tabular}

Table 5

Overall fit indices of the CFA model

\begin{tabular}{lll}
\hline Fit index & Scores & Recommended cut-off value \\
\hline Absolute fit index & & \\
\hline Chi-Square/df & 2.71 & $>=3$ \\
GFI & 0.97 & \\
AGFI & 0.93 & \\
\hline Comparative fit Indices & & $>=0.9$ \\
\hline NFI & 0.97 & $>=0.9$ \\
CFI & 0.91 & \\
\hline Parsimonious fit Indices & & $<0.08$ \\
RMSEA & 0.06 & The higher, the better \\
PGFI & 0.85 & The higher, the better \\
PNFI & 0.93 &
\end{tabular}




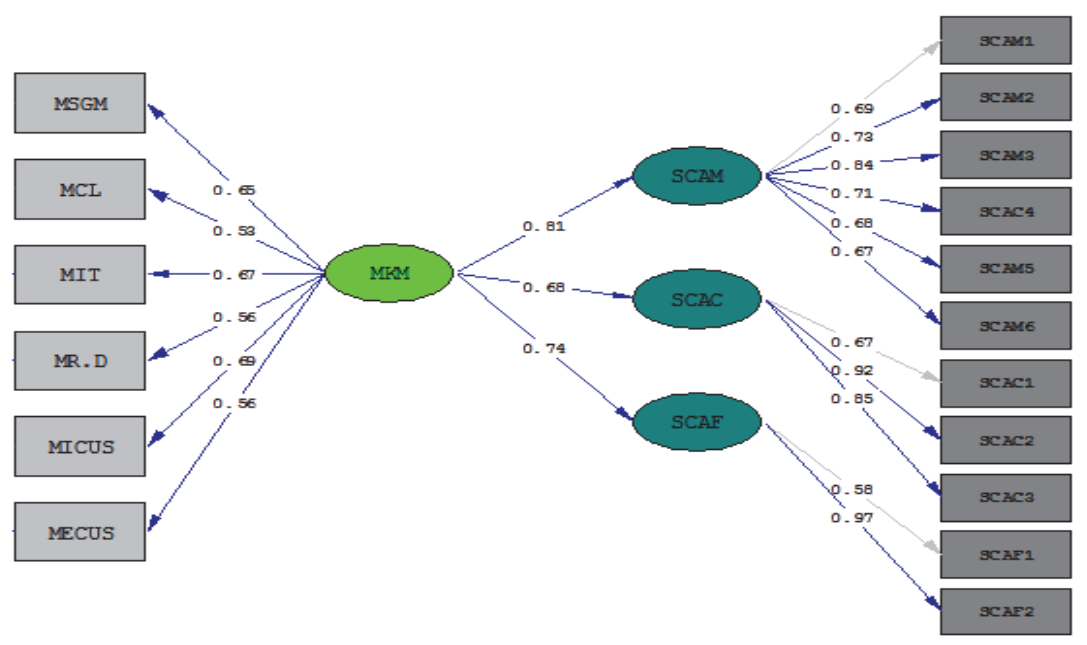

Fig. 3. Structural Relationship model between MKM and SCA

\section{Hypothesis testing}

In the hypothesis testing stage, the proposed hypotheses were examined by using the Structural Equation Modeling (SEM) technique. The findings (Table 6) for H1 (MKM to SCAM, $\gamma 11=0.77 ; p$ $<0.000$ ) implies that MKM has a positive and significant relationship with SCAM in Mellat bank. By adopting the suggested MKM practices, firms will be better able to improve on the level of SCA through a more systematic approach. This result is consistent with the findings of Akroush (2010), in which the authors found that MKM has an effect on the performance, resulting in improved SCA. Pertaining to $\mathrm{H} 2$ (MKM to SCAC; $\gamma 21=0.76 ; \mathrm{p}<0.000$ ), the findings revealed that there is a positive relationship between the dimensions of MKM and SCAC. This result is quite similar to Samat et al. (2006)'s study on the Malaysian service firms, in which the result revealed that information and communication has the greatest impact on service quality followed by other quality management practices such as customer focus, continuous improvement and empowerment. For the third hypothesis, $\mathrm{H} 3$ (MKM to SCAF, $\beta 21=0.53 ; \mathrm{p}<0.000$ ), the results were significant, implying that there is a significant relationship between MKM and SCAF. This result is consistent with the previous studies of Camarero (2007), where they found that market orientation has a positive link with service quality.

Table 6

Standardized path coefficients

\begin{tabular}{llll}
\hline Hypothesis & Estimate & $\mathrm{p}$ & Remarks \\
\hline $\mathrm{H}_{1}$ & 0.77 & $<0.000$ & Supported \\
$\mathrm{H}_{2}$ & 0.76 & $<0.000$ & Supported \\
$\mathrm{H}_{3}$ & 0.53 & $<0.000$ & Supported \\
\hline
\end{tabular}

\section{Discussion}

This study investigates the associations between MKM and SCA for the banking industry. This paper serves as empirical evidence contributing to the attributes of MKM that can be seen on SCA in three areas including the market, costumer and financial. From the analysis, it was shown that MKM contributes significantly and positively to SCA. In other words, MKM implementation can improve the SCA of the Mellat bank. Our findings are consistent with the studies performed by Kheri (2012). That 
study supported the strong positive linkage between MKM and SCA since MKM can mediate the firm's VRIN resources to improve performance and reach sustainable competitive advantage. Furthermore, Veismoradi et al. (2013) findings about MKM principles which serve as an apparatus for a company to achieve SCA have also been supported by our study. The practices of MKM used in our study, are somewhat similar to those used by Akroush (2010), Veismoradi et al. (2013) and Jafari and rezaee (2014). Thus, once MKM practices are in place, market needs can be identified easily and marketing strategy can be further improved, creating values for the customers and accordingly, increase company profits. In other words, market-centered banks have the ability to understand their market targets better. They are more committed to provide premium service quality to their customers. And also, their efforts can lead to the provision of high quality service, which will then result in enhanced company performance. Generally, market-centered service firms are better able to meet the needs and expectations of their customers by providing superior service quality. In summary, when MKM dimensions are present in the bank, Banks will be prompt, proper and reliable, thus enhancing the assurance of the bank's services towards the customers. Consequently, increase their profits and productivity. From a managerial perspective, the findings of the current study guide the banks to a better understanding of the importance of MKM in their managerial actions in becoming a truly market, customer and financial centred. Hence, it is imperative for service providers to devote more attention to embrace MKM as a vital management tool for improving competitiveness. Put it simply, in a view of the highly competitive service environment, service practitioners should emphasize on MKM as a feasible change management tool to achieve a greater degree of SCA within their banks. Consequently, banks should constantly monitor the competitive service markets and response to changes better than their rivals do. Furthermore, this study shows that the role of MKM has expanded and contributed to SCA.

\section{References}

Abishovna, B. A. (2014). The Principle of Effective Marketing Management.Procedia-Social and Behavioral Sciences, 109, 1322-1325.

Akroush, M. (2006). Effects of marketing assets and capabilities on performance: An empirical investigation of banks operating in Jordan. Jordan Journal of Business Administration, 2(3), 440463.

Alavi, M., \& Leidner, D. (2001). Knowledge management and knowledge management systems: Conceptual foundations and research issues. MIS Quarterly, 25(2), 107-136.

Akroush, M., \& Al-Mohammad, S. (2010). The effect of marketing knowledge management on organizational performance: An empirical investigation of the telecommunications organizations in Jordan. International Journal of Emerging Markets, 5(1), 38-77.

Anderson, J.C., \& Gerbing, D.W. (1988). Structural equation modeling in practice: a review and recommended two-step approach. Psychological Bulletin, 103(3), 411-423.

Armistead, C., \& Meakins, M. (2002). A framework for practicing knowledge management. Long Range Planning, 35(1), 49-71.

Meihami, B., \& Meihami, H. (2014). Knowledge Management a way to gain a competitive advantage in firms (evidence of manufacturing companies).International Letters of Social and Humanistic Sciences, (03), 80-91.

Bagozzi, R. P., \& Yi, Y. (1988). On the evaluation of structural equation models. Journal of the academy of marketing science, 16(1), 74-94.

Buvik, A. (2001). The industrial purchasing research framework: a comparison of theoretical perspectives from micro economics, marketing and organization science. Journal of Business \& Industrial marketing, 16(6), 439-450.

Bruton, G. D., Dess, G. G., \& Janney, J. J. (2007). Knowledge management in technology-focused firms in emerging economies: Caveats on capabilities, networks, and real options. Asia Pacific Journal of Management, 24(2), 115-130. 
Browne, M. W., \& Cudeck, R. (1992). Alternative ways of assessing model fit. Sociological Methods Research, 21(2), 230-258.

Camarero, C. (2007). Relationship orientation or service quality? What is the trigger of performance in financial and insurance services?. International Journal of Bank Marketing, 25(6), 406-426.

Choi, B., \& Lee, H. (2002). Knowledge management strategy and its link to knowledge creation process. Expert Systems with applications, 23(3), 173-187.

Choi, B., \& Lee, H. (2003). An empirical investigation of KM styles and their effect on corporate performance. Information \& Management, 40(5), 403-417.

Carrillo, P. M., Robinson, H. S., Anumba, C. J., \& Al-Ghassani, A. M. (2003). IMPaKT: A framework for linking knowledge management to business performance. Electronic Journal of Knowledge Management, 1(1), 1-12.

Cepeda Carrión, G., Luis Galán González, J., \& Leal, A. (2004). Identifying key knowledge area in the professional services industry: a case study. Journal of Knowledge Management, 8(6), 131-150.

Darroch, J. (2005). Knowledge management, innovation and firm performance.Journal of Knowledge Management, 9(3), 101-115.

Darvisha, H., Jafari, L. D., Saremic, M. R., Kafashzadehd, A. R., Hawari, M., \& Al-Sukkar, A. (2008). Is Jordan ready to have a knowledge management practice (KMP)?. Proceedings to the 4th International Conference on Technology, Knowledge and Society, Northeastern University, Boston, MA, January 18-20.

Dennis, B. A., \& Michael, C.W. (2014). The role of tacit knowledge exchange between sales and marketing. Journal of Business Research, 67(3), 324-331.

Fain, N., Kline, M., \& Duhovnik, J. (2011). Integrating R\&D and marketing in new product development. Journal of Mechanical Engineering, 7(5), 599-609.

Faraji, J. (2011). The effect of marketing knowledge management on enterprises performance at Kermanshah, Thesis of Master's Degree in Business Administration, Islamic Azad University Kermanshah Branch, Iran.

Farzad, A., Nahavandi, N., \& Caruana, A. (2008). The effect of internal marketing on organizational commitment in Iranian banks. American Journal of Applied Sciences, 5(11), 1480-1486.

Gupta, A. K., Raj, S. P., \& Wilemon, D. (1986). A Model for studying R\&D - marketing interface in the product innovation process. Journal of Marketing, 50, 7-17.

Grant, R. M. (1996). Toward a knowledge-based theory of the firm. Strategic management journal, 17(S2), 109-122.

Hou, J. J., \& Chien, Y. T. (2010). The effect of market knowledge management competence on business performance: a dynamic capabilities perspective. International Journal of Electronic Business Management, 8(2), 96-109.

Jafari, M., \& Rezaee, F. (2014). The effect of resource based view on sustainable capability advantage. Management Science Letters, 4(12), 2537-2554.

Kheiri, B., Razipour, H., \& Mirabi, V. R. (2012). Impact of marketing knowledge management on organizational performance (with respect to Pharmaceutical Organizations). Journal of American Science, 8(9), 212-219.

Lin, C. P. (2007). To share or not to share: Modeling tacit knowledge sharing. Journal of Business Ethics, 70(4), 411-428.

Lin, C., \& Tseg, S. (2005). Bridging the implementation gaps in the knowledge management system for enhancing corporate performance. Expert Systems with Applications, 29, 163-73.

Tsai, M., \& Shih, C. (2004). The impact of marketing knowledge management among managers on marketing capabilities and business performance. International Journal of Management, 21(4), 8193.

Tanriverdi, H. (2005). Information technology relatedness, knowledge management capability, and performance of multibusiness firms. MIS Quarterly, 29(2), 311-34.

Madu, C. N., Kuei, C. H., \& Jacob, R. A. (1996). An empirical assessment of the influence of quality dimension on organizational performance. International Journal of Production Research, 34(7), 1943-1962. 
Malek Zade, G. (2007). Knowledge management and economical attitudes. Technology Growth Magazine, 13(2), 349-362.

McEvily, S. K., \& Chakravarthy, B. (2002). The persistence of knowledge-based advantage: an empirical test for product performance and technological knowledge. Strategic management journal, 23(4), 285-305.

Michael, H. Z. (1999). Developing a knowledge strategy, developing a knowledge strategy. California Management Review, 41(3), 125-145.

Moustaghfir, K. (2008). The dynamics of knowledge assets and their link with firm performance. Measuring Business Excellence, 12(2), 10-24.

Darvish, H., Dehkordi, L., Saremi, M., Kafashzadeh, A., \& Faradonbeh, M. (2013). An empirical study to investigate the effects of internal and external knowledge management on dynamic organizational skills through information technology tools. Management Science Letters, 3(4), 1239-1244.

Murgolo-Poore, M. E., Pitt, L. F., \& Berthon, P. R. (2003). Three Theoretical Perspectives on One of Marketing's Most Fundamental Exchanges Propositions on Personal Relationships. Marketing Theory, 3(2), 235-265.

Nunnally, J.C., \& Bernstein, I.H. (1994). Psychometric Theory. McGraw-Hill: New York.

Oliver, RL. (1999). Whence consumer loyalty? Journal of Marketing, 63, 33-44.

Razali, N.M., \& Wah, Y.B. (2011). Power comparisons of Shapiro-Wilk, Kolmogorov-Smirnov, Lilliefors and Anderson-Darling tests. Journal of Statistical Modeling and Analytics, 2(1), 21-33.

Samat, N., Ramayah, T., \& Mat Saad, N. (2006). TQM practices, service quality, and market orientation: Some empirical evidence from a developing country. Management Research News, 29(11), 713-728.

Song, M., \& Thieme, R. J. (2006). A cross-national investigation of the R\&D-marketing interface in the product innovation process. Industrial Marketing Management, 35(3), 308-322.

Spender, J. C., \& Grant, R. M. (1996). Knowledge and the firm: overview.Strategic management journal, 17(S2), 5-9.

Veismoradi, A., Akbari, P., \& Mohammadi, A. (2013). The Study Relationship between Marketing Knowledge Management Assets and Capabilities and Banking Industry Performance of Iran (Case Study: Saderat Bank of West Country). International Journal of Management and Humanity Sciences, 2(1), 25-34.

Young, T. (2006). Implementing a knowledge retention strategy. Knowledge Management Review, 9(5), 28. 